\title{
Design and Stress Analysis of Nose Landing Gear Barrel (NLGB) of a typical naval trainer aircraft
}

\author{
Praveen Joel $\mathrm{P}^{1}$, Dr. Vijayan $\mathrm{R}^{2}$ \\ ${ }^{I}$ (Computer Aided Design, Government College of Engineering, Salem, India) \\ ${ }^{2}$ (HOD/Mechanical Engineering, Government College of Engineering, Salem, India)
}

\begin{abstract}
During the conceptual design phase of aircraft the integration of undercarriage system is very important and it is often difficult to achieve on the first time. The nose wheel landing gear preferred configurations for light naval trainer aircraft. The main objective of this project is to improve the static strength criteria and fatigue life of Nose Landing Gear Barrel considered. The investigations includes preliminary design layout for Nose Landing Gear Barrel and initial sizing has been done. It has been designed and evaluated for strength criteria. A method of analysis for the design of Nose Landing Gear Barrel made up of Al-Cu alloy (BS L 168 T6511) with static loads of axial, bending and normal loads are applied. The geometric modeling of the Nose Landing Gear Barrel was carried out using CAD package CATIA V5 R19 and pre and post processing was done through MSC/PATRAN. The stresses and displacements are obtained with the application of MSC/NASTRAN finite element software.
\end{abstract}

\section{INTRODUCTION}

The Landing gear is the structure that supports an aircraft on the ground and allows it to taxi, take-off and land .The Landing gear system consists of the main landing gear and nose landing gear. Each landing gear includes a shock strut with two and tire assemblies. Tires and the wheel absorbs the original impact on landing and are the principal part of the aircraft involved in the ground control. It allows more forceful application of the brakes without the danger of nosing the aircraft over.

Tricycle is the most widely used landing gear configuration. The wheels aft of the aircraft cg is very close to it and carries much of the aircraft weight and load, thus is referred to as the main wheel. Two main gears are in the same distance from the $\mathrm{cg}$ in the $\mathrm{x}$-axis and the same distances in $\mathrm{y}$-axis, thus both are carrying the same load. The forward gear is far from cg, hence it carries much smaller load. The share of the main gear from the total load is about 80 to 90 percent of the total load, so the nose gear is carrying about 10 to 20 percent. This arrangement is sometimes called nose-gear. Both main and nose gears have the same height, so the aircraft is level on the ground, although the main gears often tends to have larger wheels. This allows the floor to be flat for passenger and cargo loading. Unlike tail-gear, a nose gear configuration aircraft is directionally stable on the ground as well as during taxing. The reason is that if the aircraft yaws slightly while taxiing, the rolling and skidding resistance of the main gear, acting behind the cg, tends to straighten the aircraft out.

\section{GEOMETRIC MODELING}

CATIA V5 is design software developed by Dassaults systems to meet the complicated design requirements in the field of aerospace and automotive. In this project, CATIA V5 have been used as a main design tool to develop Nose Landing Gear Barrel (NLGB).

The follwing work benches have been used to construct the nose Landing Gear Barrel (NLGB). They are:

Sketcher bench consists following tools:

Sketch tools: to modify the work space. Profile tools: to create the basic shapes. Constraint: to lock the shape with respect to an axis. Operation: to fillet,chamfer etc.

Part bench is used to convert the 2 dimensional view to 3 dimensional which is obtained from the sketcher bench. Some tools are used to convert 2D to 3D such as pad, pocket, fillet, chamfer.

Pad which convert 2D to 3D according to the desired direction. Pad can be done in forward or reverse direction. Depth and thickness can be varied according to given values.

Pocket is the tool in which surface is reduced by the cutting option. It will reduce the thickness.

The edges should be curved to reduce the stress concentration of the object for that we use the fillet tool. It will minimize the stress concentration which is an important function. All the edged surfaces can be curved using this tool. 


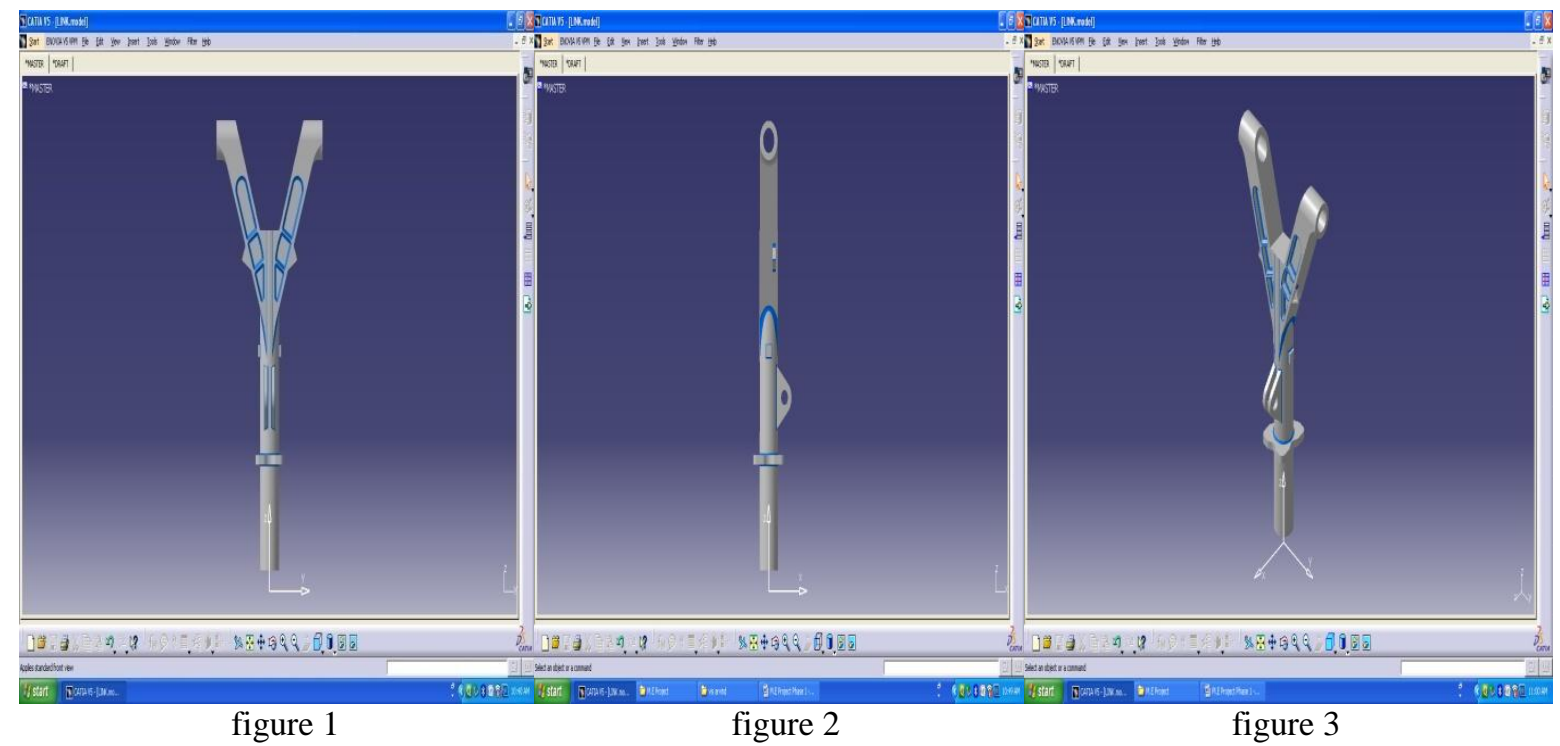

III. FINITE ELEMENT MODEL

The geometry model of landing gear was created using CATIAV5 R12 software and the extension of filename.model has been created \& imported to MSC/ PATRAN, which is shown in the following figure 4. The finite element model of landing gear barrel is created using 3D solid tetrahedron 10 element through the preprocessing of MSC/Patran. The holes in the barrel are filled with RBE3 Element inorder to distribute the load from connected pin to the barrel. The Finite Element Mesh is given in figure 5.

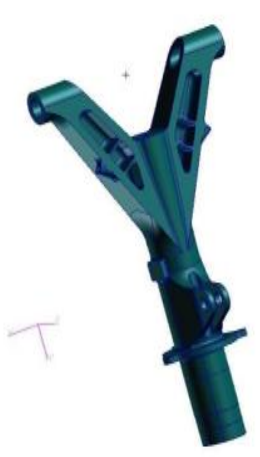

figure 4

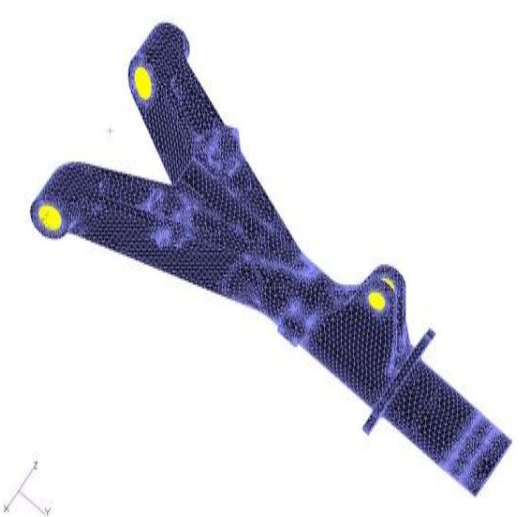

figure 5

\section{LOADS AND BOUNDARY CONDITIONS}

One would presume that the landing gear is subjected to highest loads during loading, but in reality landing conditions are critical for only about $20 \%$ of the landing gear structure. The ground handling conditions, especially turning and taxiing are critical for the rest of structure. This is the enlarged view of the right portion of the landing gear barrel in figure 6 is meshed with Tet 10 element. Inside the hole, BAR elements are used to transfer the load in the landing gear barrel. The loads acting on the landing gear barrel, right and left of the barrel is given in the below table. The axial load (Fx) applied at the centre of the barrel by dividing it with the number of nodes, the normal loads are applied by creating the bar elements inside the barrel hole. The load is applied on the retractable leg. The Inplane boundary conditions are all applied on the bottom of the barrel and in centre of the retractable arm.

\begin{tabular}{|l|l|l|l|l|l|l|l|l|l|}
\hline Loads N & R1V & R1D & R1S & R2V & R2D & R2S & DBV & DBD & DBS \\
\hline Limit & 190 & -1470 & 0 & 190 & -1470 & 0 & 3876 & 6034 & 0 \\
\hline Ultimate & 285 & -2205 & 0 & 285 & -2205 & 0 & 5814 & 9015 & 0 \\
\hline
\end{tabular}

Spring-back load case

\begin{tabular}{|l|l|l|l|l|l|l|l|l|l|}
\hline Loads N & R1V & R1D & R1S & R2V & R2D & R2S & DBV & DBD & DBS \\
\hline Limit & 5185 & 1895 & 0 & 5185 & 1895 & 0 & -4186 & -6517 & 0 \\
\hline Ultimate & 7777.5 & 2842.5 & 0 & 7777.5 & 2842.5 & 0 & -6279 & -9775.5 & 0 \\
\hline
\end{tabular}

Maximum Vertical Loading case 
Design and Stress Analysis of Nose Landing Gear Barrel (NLGB) of a typical naval trainer aircraft

\begin{tabular}{|l|l|l|l|l|l|l|l|l|l|}
\hline Loads N & R1V & R1D & R1S & R2V & R2D & R2S & DBV & DBD & DBS \\
\hline Limit & 2140 & -459 & 0 & 2140 & -459 & 0 & 1521 & 2367 & 0 \\
\hline Ultimate & 3210 & -688.5 & 0 & 3210 & -688.5 & 0 & 2281.5 & 3550.5 & 0 \\
\hline
\end{tabular}

Turning right load case

\begin{tabular}{|l|l|l|l|l|l|l|l|l|l|}
\hline Loads N & R1V & R1D & R1S & R2V & R2D & R2S & DBV & DBD & DBS \\
\hline Limit & -1150 & 80 & 0 & 2856 & 80 & 801 & -103 & -160 \\
\hline Ultimate & -1725 & 120 & 0 & 4284 & 120 & 1201.5 & -1545 & -240 & 0 \\
\hline
\end{tabular}

Turning left load case

\begin{tabular}{|l|l|l|l|l|l|l|l|l|l|}
\hline Loads N & R1V & R1D & R1S & R2V & R2D & R2S & DBV & DBD & DBS \\
\hline Limit & 2856 & 80 & -801 & -1152 & 80 & 0 & -103 & -160 \\
\hline Ultimate & 4284 & 120 & -1201.5 & -1728 & 120 & 0 & 0 & -154.5 & -240 \\
\hline
\end{tabular}

Point braked roll at wto load case

\begin{tabular}{|l|l|l|l|l|l|l|l|l|l|}
\hline Loads N & R1V & R1D & R1S & R2V & R2D & R2S & DBV & DBD & DBS \\
\hline Limit & 2027 & 1920 & 0 & 2027 & 1920 & 0 & -246 & -383 \\
\hline Ultimate & 3040.5 & 2880 & 0 & 3040.5 & 2880 & 0 & -369 & -574.5 & 0 \\
\hline
\end{tabular}

$3 \mathrm{~g}$ taxiing load case

\begin{tabular}{|l|l|l|l|l|l|l|l|l|l|}
\hline Loads N & R1V & R1D & R1S & R2V & R2D & R2S & DBV & DBD & DBS \\
\hline Limit & 2556 & 240 & 0 & 2556 & 240 & 0 & -308 & -479 & 0 \\
\hline Ultimate & 3834 & 360 & 0 & 3834 & 360 & 0 & -462 & -718.5 & 0 \\
\hline
\end{tabular}

Towing forward load case

\begin{tabular}{|l|l|l|l|l|l|l|l|l|l|}
\hline Loads N & R1V & R1D & R1S & R2V & R2D & R2S & DBV & DBD \\
\hline Limit & 2556 & 240 & 0 & 2556 & 240 & 0 & -308 & -479 \\
\hline Ultimate & 3834 & 360 & 0 & 3834 & 360 & 0 & -462 & -718.5 & 0 \\
\hline
\end{tabular}

Towing aft load case

\begin{tabular}{|c|c|c|c|c|c|c|c|c|c|}
\hline Loads N & R1V & R1D & R1S & R2V & R2D & R2S & DBV & DBD & DBS \\
\hline Limit & -1443 & -1434 & 0 & -1443 & -1434 & 0 & 4381 & 6819 & 0 \\
\hline Ultimate & -2164.5 & -2151 & 0 & -2164.5 & -2151 & 0 & 6517.5 & 10228.5 & 0 \\
\hline
\end{tabular}

Towing side (1) load case

\begin{tabular}{|l|l|l|l|l|l|l|l|l|l|}
\hline Loads N & R1V & R1D & R1S & R2V & R2D & R2S & DBV & DBD & DBS \\
\hline Limit & -3009 & 750 & 0 & 4601 & 750 & 1976 & -97 & -150 \\
\hline Ultimate & -4513.5 & 1125 & 0 & 6901.5 & 1125 & 2964 & -145.5 & -225 \\
\hline
\end{tabular}

Towing side (2) load case

\begin{tabular}{|l|l|l|l|l|l|l|l|l|l|}
\hline Loads N & R1V & R1D & R1S & R2V & R2D & R2S & DBV & DBD & DBS \\
\hline Limit & 4601 & 750 & -1976 & -3009 & 750 & 0 & -97 & -150 \\
\hline Ultimate & 6901.5 & 1125 & -2964 & -4513.5 & 1125 & 0 & 0 & -145.5 & -225 \\
\hline & & & & & & & & & \\
\hline
\end{tabular}

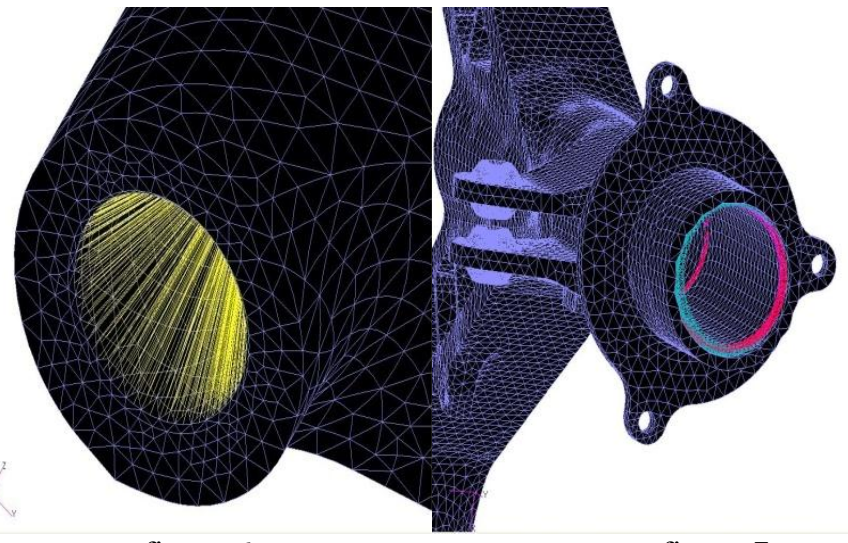

figure 6 figure 7

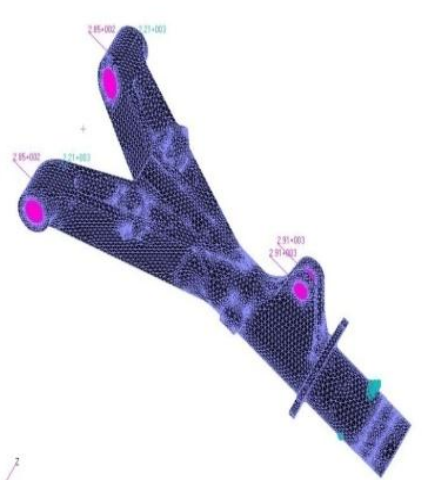

figure 8 


\section{MATERIAL}

Aluminium -Copper Alloy (BS L 168 T6511) includes copper (Cu) as the major alloying element. Silicon $(\mathrm{Si})$, manganese $(\mathrm{Mn})$, magnesium $(\mathrm{Mg})$, nickel $(\mathrm{Ni})$ and titanium $(\mathrm{Ti})$ may be added to the alloys of $2 \mathrm{xxx}$ series as minor alloying elements. Aluminium-copper alloys are heat-treatable. Solution treatment followed by either artificial or natural aging allows considerable increasing the yield strength (4-6 times). Ductility of the alloy decreases as a result of the heat treatment. Hardening of the alloys from this group is achieved due to precipitation of the phase $\mathrm{A} 12 \mathrm{Cu}$ occurring during aging. Alloys of this series have very high mechanical strength after heat treatment and low corrosion resistance. For increasing corrosion resistance of parts made of aluminum-copper alloys they are clad with pure aluminium. Aluminium-copper alloys are used in aircraft structures and propellers, automotive bodies, screw fittings.

\section{STATIC STRESS ANALYSIS}

The job is submitted for the analysis. The required output files are selected. The *.bdf file is generated. Processing is done using MSC/NASTRAN.

$$
>\text { filename.bdf } \mathrm{scr}=\text { yes old=no news=no }
$$

The *.fo6 file is created and it is opened using notepad to search for fatal error and warnings. If there is no fatal and warning, then we can conclude that the job is completed without error. The software MSC/NASTRAN tool calculates global stiffness matrix elemental forces from the data given in loads and boundary conditions. Then the job is subjected to analysis using MSC/NASTRAN. It interprets the matrices for the geometry and gives the displacements, stresses and strains for the model. The results can be verified by cross checking the reaction obtained from manual calculations and the reaction in the *.fo6 file is submitted to the MSC PATRAN for the post processing. The maximum principal stress plot and displacement plot for concentrated load applied at the LANDING GEAR is shown and the load is applied at the edge of the nodes is shown. The stress plot for both cases is found to be similar.

Spin up:

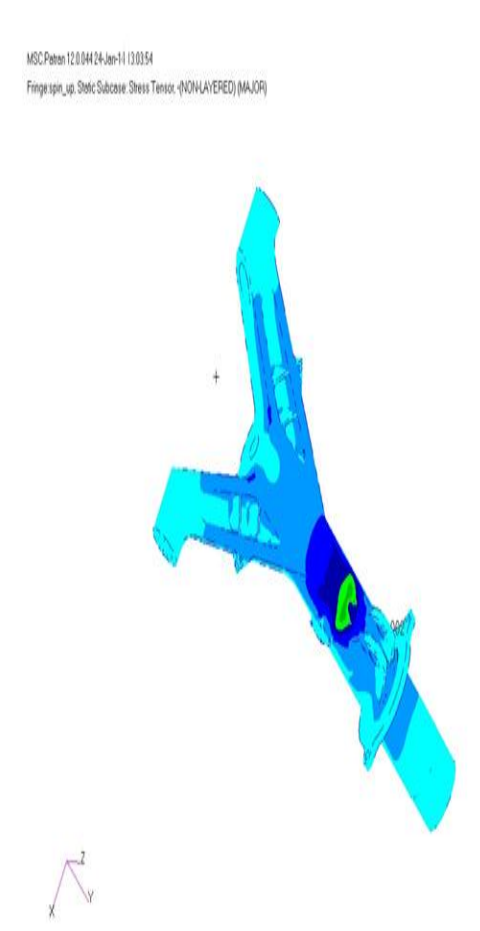

figure 9

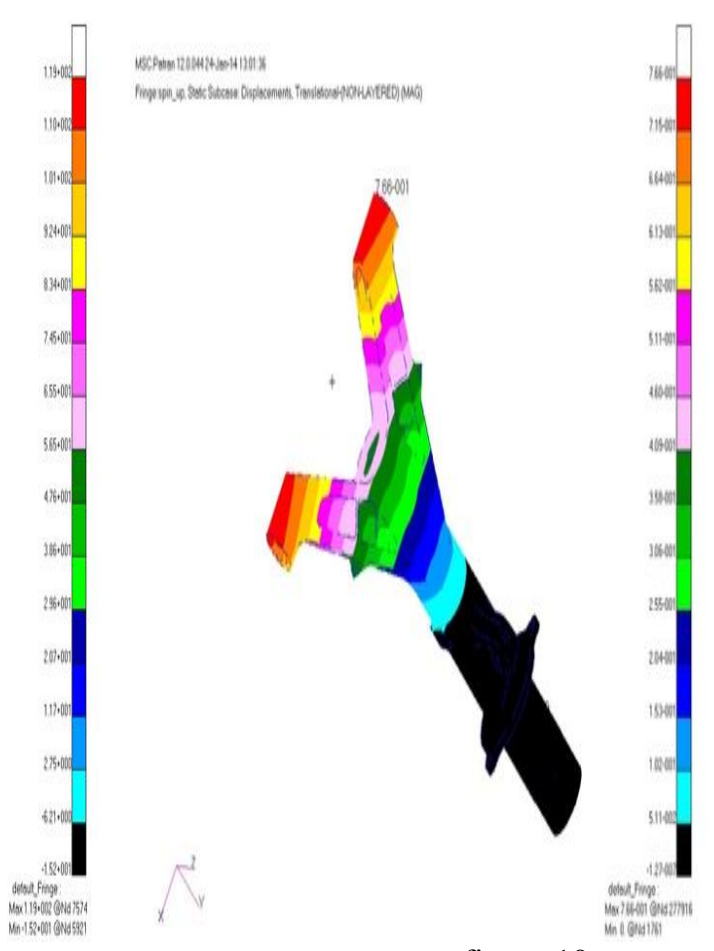

figure 10 
Spring back:

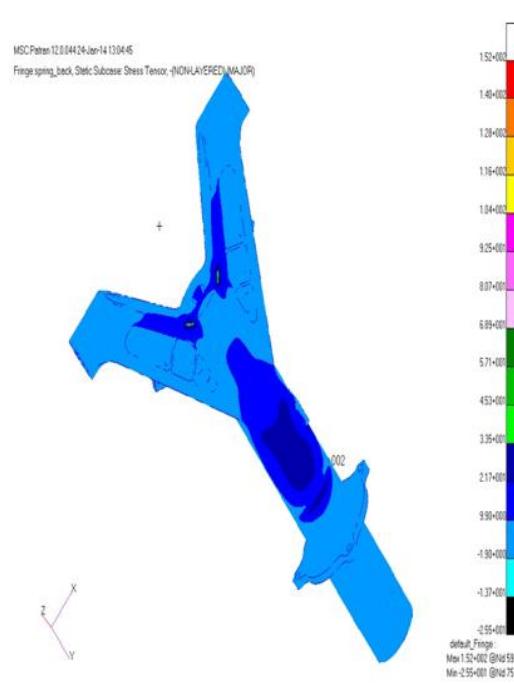

figure 11

Maximum vertical loading:

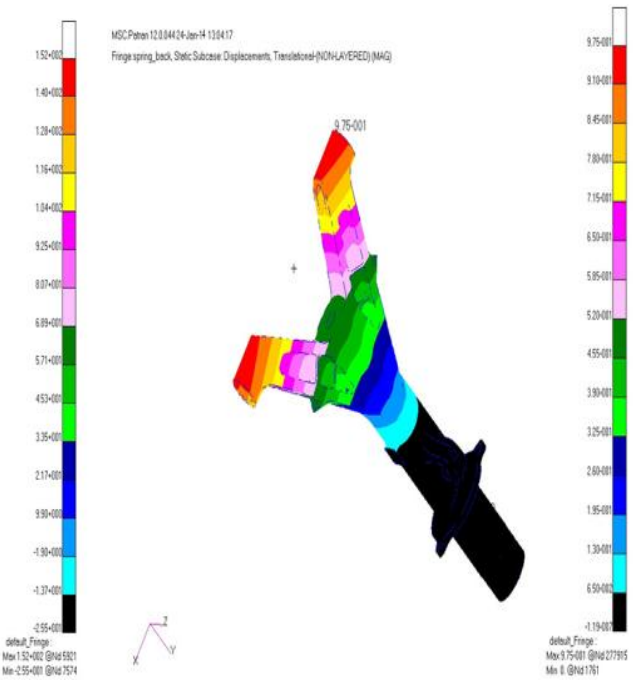

figure 12

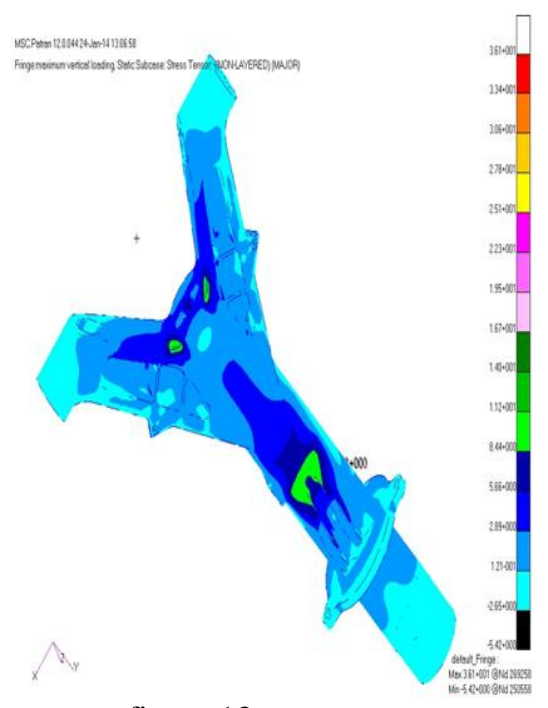

figure 13

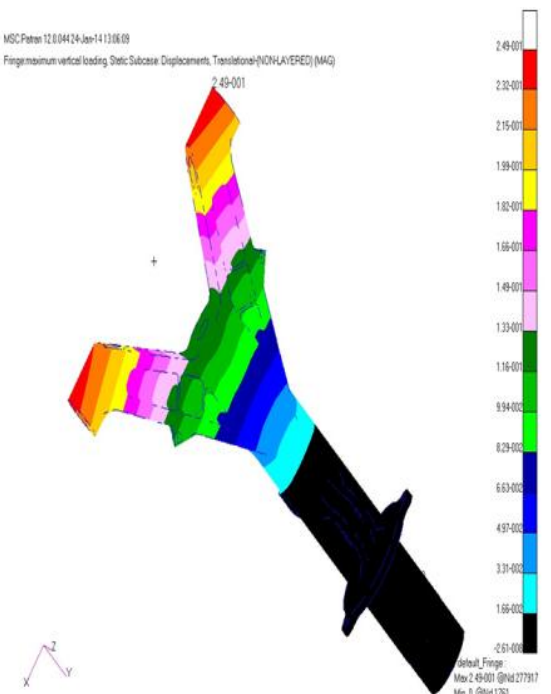

figure 14

Turning right load case:

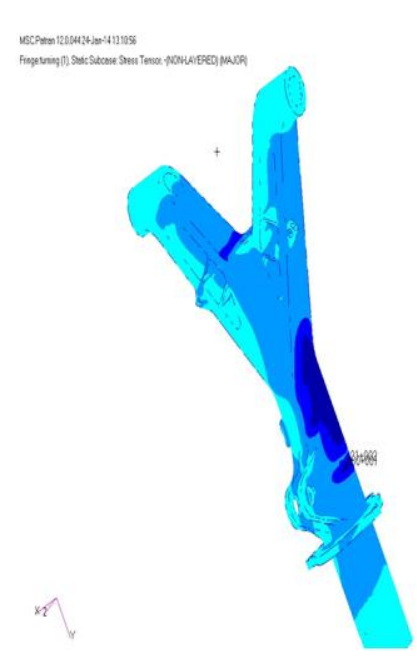

figure 15

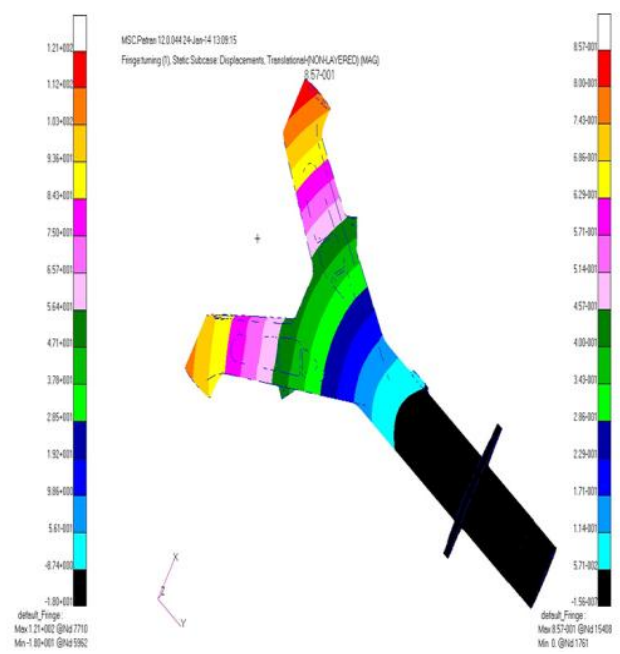

figure 16 
Turning left load case:

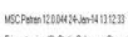

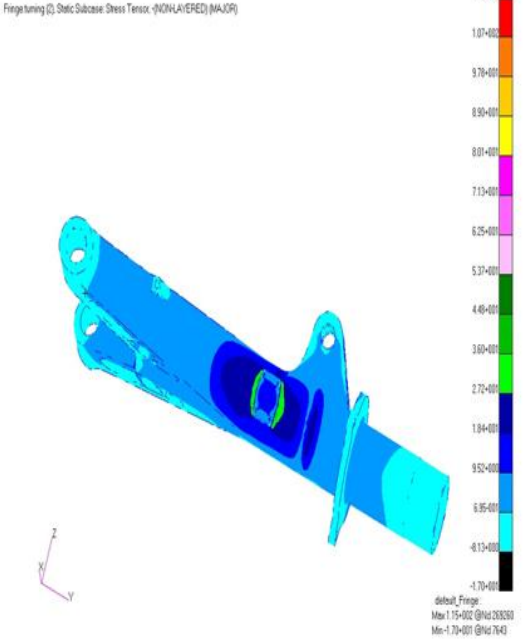

figure 17

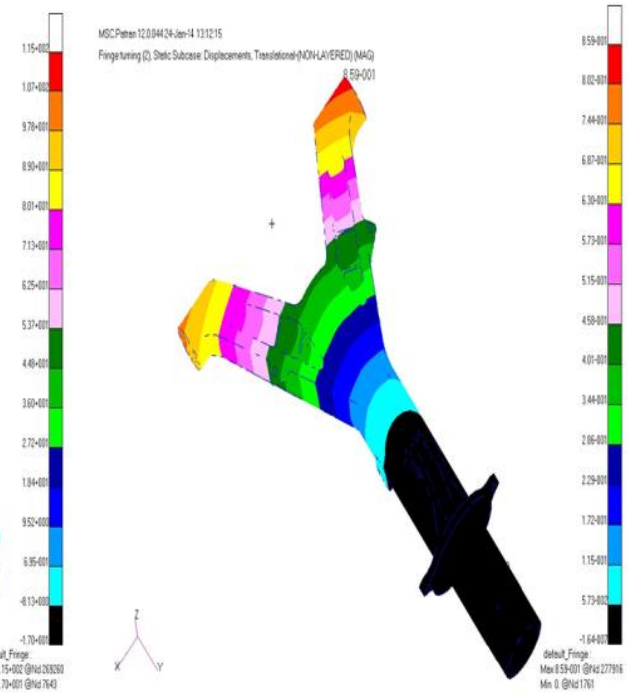

figure 18

Point Braked Roll at WTO Load case:

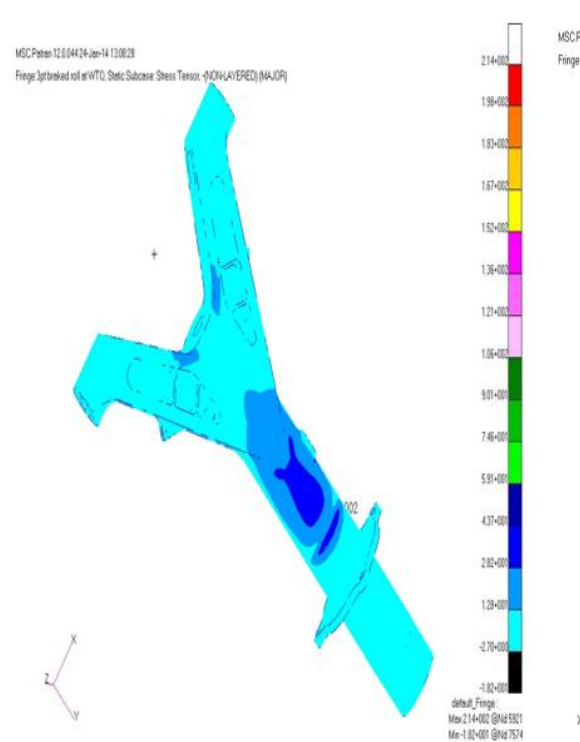

figure 19 $\times$

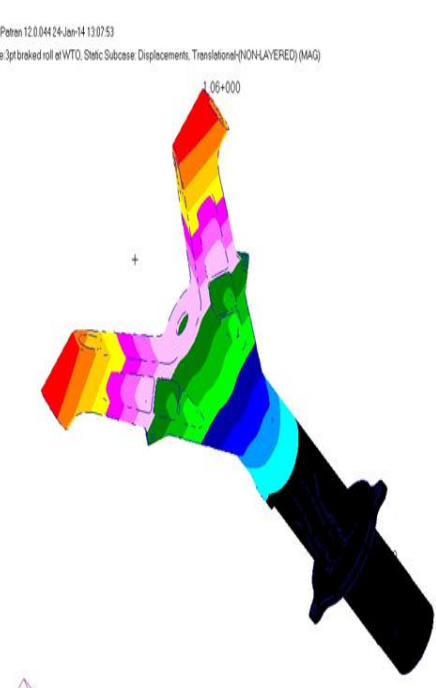

figure 20

3G Taxiing Load case:

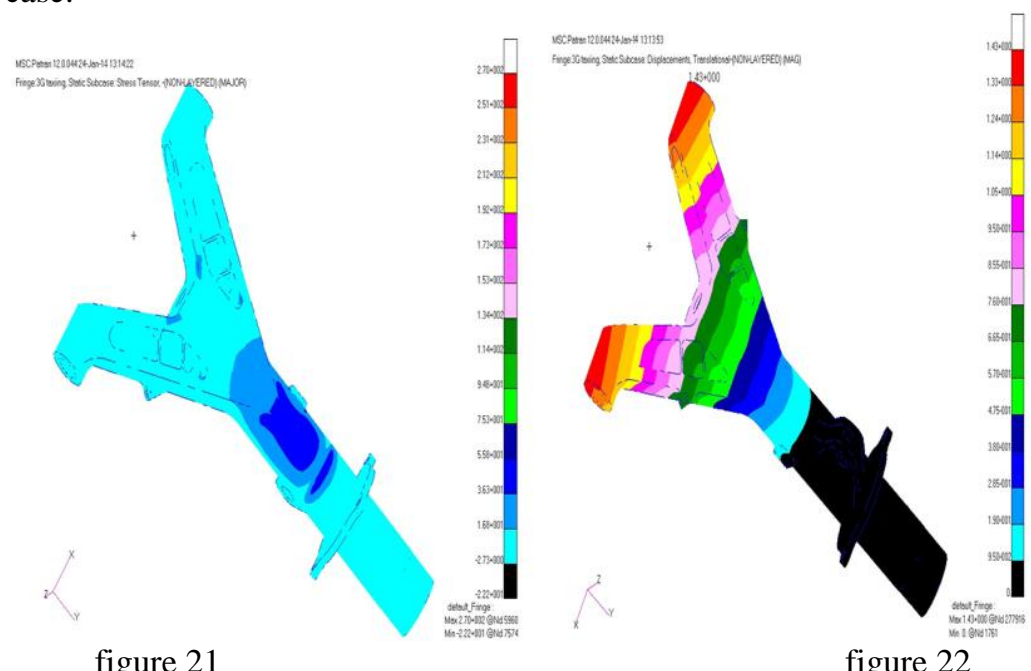


Towing Forward load case:

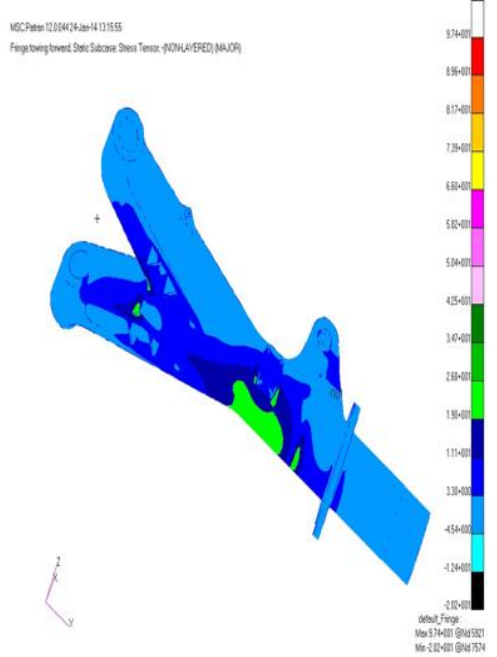

figure 23

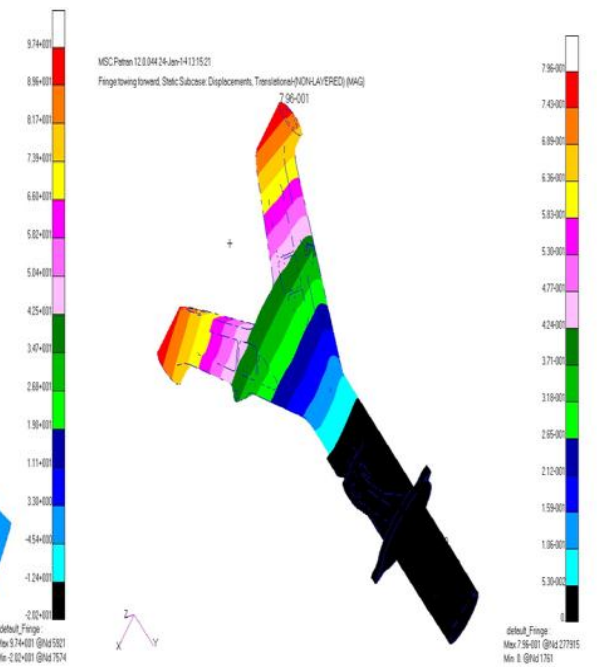

figure 24

Towing Aft Load Case:

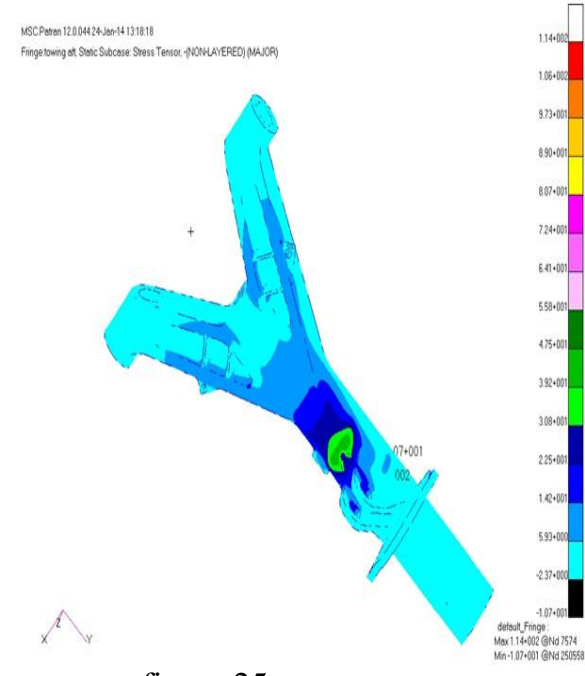

figure 25

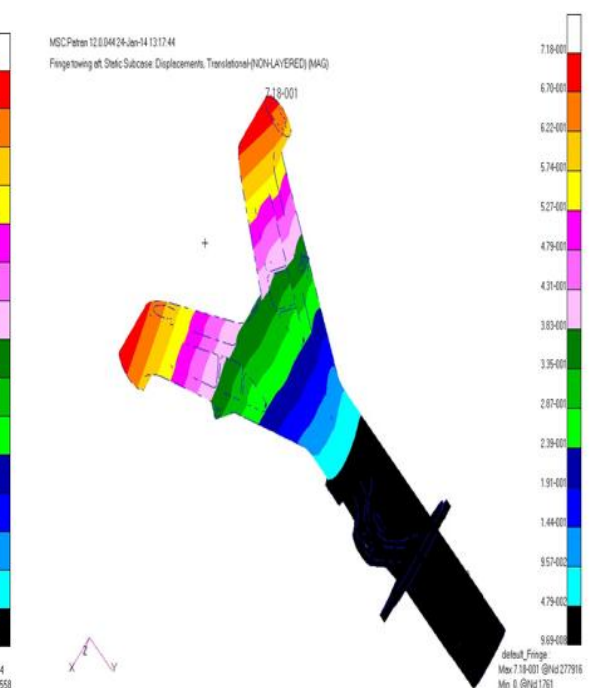

figure 26

Towing side (1) Load case:

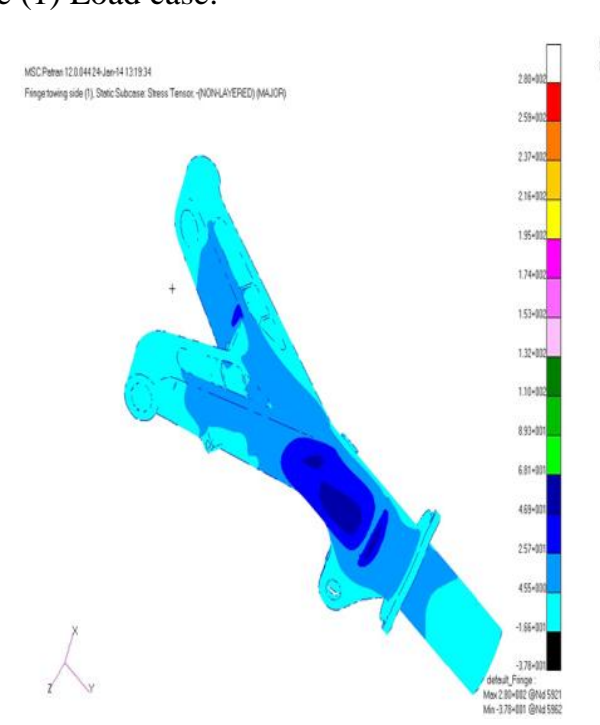

figure 27

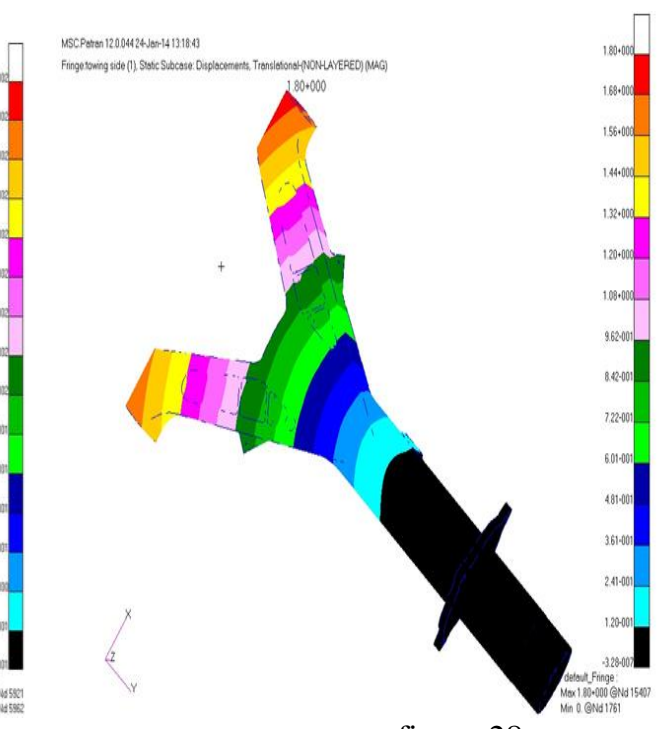

figure 28 
Towing side (2) Load case:

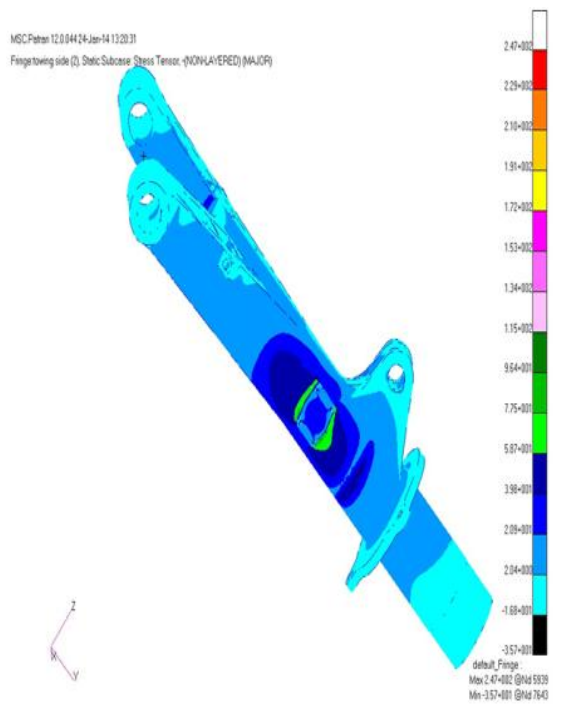

figure 29

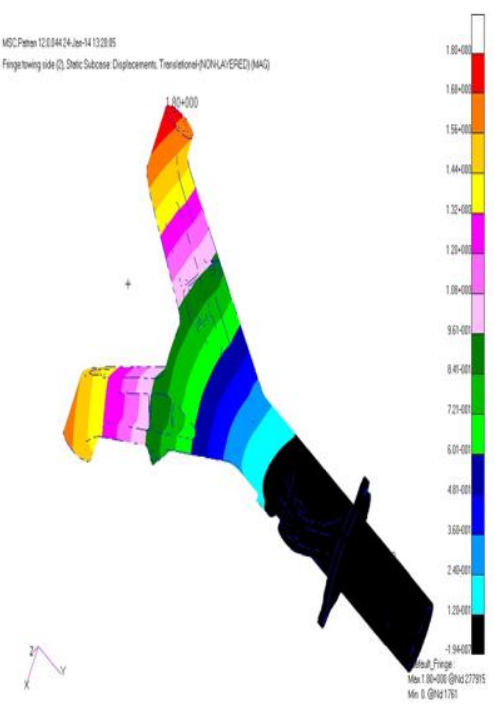

figure 30

Stress \& reserve factor calculations:

\begin{tabular}{|l|l|l|l|l|l|}
\hline S.No & Load case & Displacement & $\begin{array}{l}\text { Max Principal } \\
\text { Stress MPA }\end{array}$ & $\begin{array}{l}\text { Ultimate Tensile } \\
\text { Strength }\end{array}$ & Reserve Factor \\
\hline 1 & spin up & 0.76 & 119 & 460 & 3.86 \\
\hline 2 & spring back & 0.975 & 152 & 460 & 3.02 \\
\hline 3 & max vertical landing & 0.249 & 36.1 & 460 & 12.74 \\
\hline 4 & 3 point braked roll & 1.06 & 214 & 460 & 2.15 \\
\hline 5 & turning 1 & 0.857 & 121 & 460 & 3.80 \\
\hline 6 & turning2 & 0.859 & 115 & 460 & 4 \\
\hline 7 & 3 taxiing & 1.43 & 270 & 460 & 1.70 \\
\hline 8 & towing forward & 0.796 & 97.4 & 460 & 4.72 \\
\hline 9 & towing aft & 0.718 & 114 & 460 & 4.04 \\
\hline 10 & towing side 1 & 1.8 & 280 & 460 & 1.64 \\
\hline 11 & towing side 2 & 1.8 & 247 & 460 & 1.86 \\
\hline
\end{tabular}

\section{CONCLUSION \& FUTURE WORKS}

Stress analysis of a Landing gear barrel of typical fighter aircraft is carried out using finite element software package MSC PATRAN and MSC/NASTRAN.

The maximum principal stress in the barrel is obtained for all the landing load cases stresses are compared with material allowable stress of $460 \mathrm{mpa}$. the calculated reserve factor are more than the required value of one. hence the component is safe from static strength criteria. Further the model will be submitted for fatigue analysis and structural optimization in order to predict safe landings in future.

\section{REFERENCES}

\section{Journal Papers:}

[1] Avinash V. Gaikwad, Rajesh U. Sambhe, Pravin S. Ghawade, Modeling and Analysis of Aircraft Landing gear: Experimental Approach, International Journal of Science and Research, 7(2), July 2013, ISSN 2319-7064.

[2] Ajayi J. A, Joseph O. O, Oloruntoba D. T \& Joseph O. O, Experimental failure investigation of an Aircraft Nose Landing gear, Books: International Journal Metalurgical \& Materials Science and Engineering, 1(3), March 2013, 85-92.

[3] Norman S. Currey, Aircraft landing gear design: Principles and practices (AIAA Education Series, 1988).

[4] H. G. Conway, Landing gear design (The royal aeronautical society, Chapman \& Hall Ltd, 1958).

[5] Nitin S Gokhale, Sanjay S Deshpande, Sanjeev V Bedekar, Anand N Thite, Practical Finite Element Analysis (Dr Peter Fischer, Finite to Infinite, 2008)

[6] E. F. Bruhn, Analysis and design of flight vehicle structures (S. R. Jacobs \& Associates, Inc, 1973)

[7] Micheal C. Y. Niu, Airframe Stress Analysis and sizing (Adaso/Adastra Engineering Center; 3rd edition, October 31, 2011).

\section{Theses:}

[8] Thoai D. Nguyen, Finite Element Analysis of Nose Gear during Landing, M.S diss., University of North Florida, College of Computing, Engineering and Construction, Florida, USA, April 2010. 